\begin{tabular}{|l|l|}
\hline Las múltiples caras de la islamofobia & Titulo \\
\hline Grosfoguel, Ramón - Autor/a; & Autor(es) \\
\hline $\begin{array}{l}\text { De Raíz Diversa. Revista Especializada en Estudios Latinoamericanos (Vol. 1 no. 1 } \\
\text { abr-sep 2014) }\end{array}$ & En: \\
\hline México D.F. & Lugar \\
\hline $\begin{array}{l}\text { Programa de Posgrado en Estudios Latinoamericanos, Universidad Nacional } \\
\text { Autónoma de México }\end{array}$ & Editorial/Editor \\
\hline 2014 & Fecha \\
\hline Cultura; Sociedad; Historia; Eurocentrismo; Discriminación; Racismo; Islam; & Colección \\
\hline Artículo & Temas \\
\hline "http://biblioteca.clacso.edu.ar/Mexico/ppel-unam/20160614021642/Grosfoguel.pdi" & Tipo de documento \\
\hline $\begin{array}{l}\text { Reconocimiento-No Comercial-Sin Derivadas CC BY-NC-ND } \\
\text { http://creativecommons.org/licenses/by-nc-nd/2.0/deed.es }\end{array}$ & URL \\
\hline
\end{tabular}

Segui buscando en la Red de Bibliotecas Virtuales de CLACSO

http://biblioteca.clacso.edu.ar

Consejo Latinoamericano de Ciencias Sociales (CLACSO)

Conselho Latino-americano de Ciências Sociais (CLACSO)

Latin American Council of Social Sciences (CLACSO)

www.clacso.edu.ar

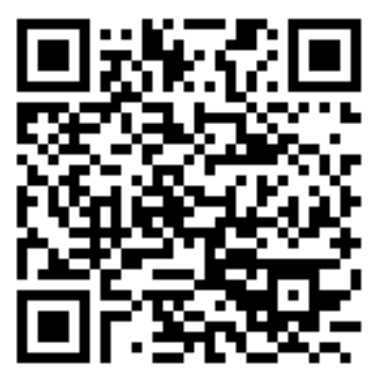




\title{
Las múltiples caras de la islamofobia
}

\author{
RAMÓN Grosfoguel *
}

Resumen: El artículo discute las múltiples manifestaciones y dimensiones de la islamofobia. Ésta es entendida como una forma de racismo que tiene larga duración en el sistema-mundo, pero resurgió con fuerza a partir del $11 \mathrm{de}$ septiembre de 2001. Dedicando especial atención a la islamofobia epistémica como una manera de racismo epistémico.

Palabras Clave: islamofobia, racismo epistémico, eurocentrismo, sistema-mundo.

Abstract. This article discusses the multiple expressions and dimensions of islamophobia. It treats islamophobia as long-durée form of racism in the worldsystem, once it re-emerged strongly after the September 11, 2001. The paper aims at highlighting a special attention to the epistemic Islamophobia as a way of epistemic racism.

KEYWORDS: islamophobia, epistemic racism, eurocentrismo, world-system.

Recibido: 07 de agosto de 2013. Aceptado: 09 de septiembre de 2013.

C ualquier debate hoy día sobre la islamofobia debe tomar como punto de partida la discusión sobre la cartografía de poder del "sistema-mundo" durante los últimos 522 años. Si entendemos el "sistema-mundo moderno" organizado exclusivamente en términos de una división internacional del trabajo y un sistema global interestatal, entonces la islamofobia sería un epifenómeno de la economía política de dicho sistema y, en particular, de la incesante acumulación de capital a escala mundial. No obstante, si cambiamos la geopolítica del conocimiento y también su corpo-política desde una mirada nordocéntrica hacia una visión orientada desde el sur global, obtendremos una imagen diferente de la cartografía global del poder. Mirado desde una perspectiva del sur global, el sistema-mundo se organiza no sólo en torno a una división internacional del trabajo y un sistema global interestatal, sino que incluye, no como aditivos, sino como elementos constitutivos de la acumulación capitalista a escala mundial, jerarquías globales como la étno/racial (occidental frente a los pueblos no-occidentales), patriarcal (un sistema global de género y un sistema

* University of California, Berkeley, <grosfogu@berkeley.edu>. 
global de sexualidad con base judeo-cristiana), religiosa, lingüística, epistémica, etcétera (Grosfoguel, 2006: 167-187). El enmarañado “paquete” de jerarquías de poder del sistema-mundo es más amplio y más complejo de lo que con frecuencia se teoriza al analizarlo. En aras de economizar espacio, cuando utilizamos en este artículo el término sistema-mundo, nos referimos al "occidentalizado moderno/colonial, cristiano-céntrico, capitalista/patriarcal” (Grosfoguel, 2006: 167-187). A riesgo de sonar ridículo, preferimos utilizar una frase extensa como ésta para caracterizar su actual estructura heterárquica (múltiples jerarquías de poder enredadas entre sí de maneras históricamente complejas), antes que la limitada caracterización de una sola jerarquía llamada "sistema-mundo capitalista", con la acumulación de capital como la única o más importante lógica sistémica (Grosfoguel, 2006: 167-187). Esta última, nos lleva a una comprensión económica reduccionista del aludido sistema, mientras que la primera comporta un análisis histórico-estructural más complejo y antirreduccionista. La tesis derivada de esta concepción es que la islamofobia como forma de racismo contra los musulmanes no es un epifenómeno, sino más bien, es constitutiva de la división internacional del trabajo.

El presente artículo se estructura en cinco partes: la primera analiza la islamofobia como una forma de racismo desde una perspectiva histórica mundial; la segunda examina la islamofobia como un modo de racismo cultural; el tercer apartado la aborda como orientalismo; el cuarto apartado atiende su dimensión de racismo epistemológico; mientras que la parte final ejemplifica lo anterior con el caso del filósofo y teólogo musulmán europeo Tariq Ramadan.

\section{LA ISLAMOFOBIA COMO UNA FORMA DE RACISMO DESDE UNA PERSPECTIVA HISTÓRICA MUNDIAL}

El reto de esta sección es responder cómo fue posible que una diferencia religiosa en el mundo "pre-moderno" llevara a otra como la racial/étnica en el mundo moderno/colonial capitalista/patriarcal. En la conceptualización heterárquica del sistema-mundo aquí empleada, la islamofobia sería la subalternización y la inferiorización racial del islam creado por la jerarquía religiosa cristiano-céntrica desde finales del siglo XV. ${ }^{1} \mathrm{El}$ año

1 La inferiorización teológica del islam es un proceso que viene del mundo premoderno, en inferiorización racial de los sujetos que practican esta espiritualidad. Lo que es nuevo en el mundo moderno es la transformación de 
1492 es fundacional y crucial para la comprensión del sistema actual, pues la monarquía cristiana española reconquistó Al-Andalus (España musulmana) expulsando y exterminando a los judíos y musulmanes de la Península Ibérica e iniciando un proceso de conversión forzosa sobre los que se quedaban. Al mismo tiempo, "descubría" las Américas y colonizaba a los pueblos indígenas. La población árabe y judía que permaneció en la Península Ibérica se vio obligada a convertirse al cristianismo. "Marranos" (los judíos conversos) y "moriscos" (los musulmanes conversos) fueron los términos utilizados en la época para clasificar la población "cristianizada". El siglo XVI estuvo marcado por la persecución dentro de la Península Ibérica contra los moriscos hasta su expulsión final en 1609 (Perceval, 1997), así como por la esclavitud de los pueblos indígenas y africanos en las Américas (Dussel, 1994). Esos territorios y pueblos conquistados en el "interior" y en el "exterior" no sólo produjeron una división internacional de trabajo capitalista con una periferia interior (la conquista de Al-Andalus en el sur de la monarquía católica española) y exterior (las Américas) que se solapaba y superponía una división internacional del trabajo étnica y racial entre occidentales y no-occidentales, sino que incluso constituyeron los límites imaginados del interior y el exterior de Europa. Esto se relaciona con la jerarquía global étnico/racial del sistema-mundo que privilegia a las poblaciones de origen europeo sobre el resto. Los judíos y los árabes se convirtieron en el otro subordinado interno "no-europeo" dentro de Europa, mientras que los pueblos indígenas y los africanos en las Américas, África y Asia se convirtieron en el otro subordinado externo de Europa.

El primer indicador de otredad en el "sistema-mundo occidentalizado, moderno/colonial, cristiano-céntrico, capitalista/patriarcal” giró en torno a la identidad religiosa. Los judíos y los árabes fueron caracterizados como "personas con la religión equivocada", y los indígenas como "gentes sin religión" (Maldonado, 2006). Visto a partir de la jerarquía global étni$\mathrm{ca} /$ racial originada por dos grandes acontecimientos ocurridos en 1492, las "gentes sin religión", es decir, las "gentes sin Dios", se ubicaban en la parte inferior de la jerarquía. Mientras que las "gentes con la religión equivocada", o sea, "con el Dios equivocado", ocupaban una posición diferente.

las viejas discriminaciones religiosas medievales en discriminación racial. Para una discusión más detallada sobre esta transmutación discursiva véase Ramón Grosfoguel (2012: 79-12 y 2013: 73-90). 
¿Cómo "la gente con la religión equivocada" (árabe-musulmanes y judíos) llegó a convertirse en "la gente inferior debajo de la línea de lo humano", en personas racialmente inferiores?

La lucha de la España cristiana contra el islam formó parte de un largo combate imperial en el Mar Mediterráneo, que se remonta a las Cruzadas. La contienda del cristianismo e islam articuló luchas interimperialistas resultado de las relaciones y los conflictos entre los imperios europeos frente a los sultanatos no-europeos y de lo que aquí caracterizaremos como contradicciones interimperiales. Mientras tanto, la lucha española posterior a 1492 contra los indígenas en las Américas articuló pugnas "coloniales", producto de las relaciones coloniales de dominación y explotación entre los pueblos europeos y los no-europeos; es decir, lo que conceptuaremos como el resultado de las contradicciones coloniales $v s$. anticoloniales. Históricamente, la expulsión de los árabes y los judíos de la España cristiana en nombre de la "pureza de sangre" fue un proceso proto-racista (aún no plenamente racista, aunque las consecuencias no fueron tan diferentes). La "pureza de sangre" no fue utilizada como un término racial, sino más bien como una técnica de poder para rastrear la ascendencia religiosa de la población. No obstante, no se convertiría en una perspectiva racista completa hasta mucho más tarde, y sólo después de su aplicación a los pueblos indígenas en las Américas.

A finales del siglo XV y principios del siglo XVI, los pueblos indígenas se caracterizaron como "gentes sin alma", lo que en el imaginario cristiano español equivalió a ser seres subhumanos o no humanos. Calificarlos por debajo de la línea de lo humano, en el nivel de los animales, convirtió a los pueblos indígenas de las Américas en los primeros sujetos racializados del mundo moderno/colonial iniciado en 1492 (Dussel, 1994). Este imaginario racista se extendió a los nuevos "pueblos sin alma", como los africanos subsaharianos, que fueron trasladados masivamente a las Américas como parte del comercio europeo de esclavos después del tristemente célebre debate entre Sepúlveda y Las Casas en la Escuela de Salamanca en 1552. Por su parte, Sepúlveda defendía que los pueblos indígenas no tenían alma, por lo tanto, no eran seres humanos y podían ser esclavizados sin que ello representara un pecado ante los ojos de Dios. Por otra parte, Las Casas sostenía que eran salvajes con alma, es decir, culturalmente inferiores, igual que un niño y, por tanto, eran seres humanos que debían ser cristianizados y no esclavizados. Ambos representan la articulación for- 
mal inicial de las dos maneras de racismo, prolongadas durante los cinco siglos posteriores. Sepúlveda ofrecía un discurso racista biológico y Las Casas uno racista cultural.

La posición de Las Casas ganó el juicio. Como consecuencia, el imperio español decidió que los "indios" fueran incorporados a la encomienda (una forma de trabajo forzado semifeudal utilizado contra los moriscos en la conquista de Al-Andalus) y la transportación masiva de africanos para sustituirlos como esclavos en las plantaciones. Después de todo, los africanos fueron caracterizados como "gentes sin alma". El razonamiento versó en que el imaginario racista construido en contra de los indígenas del Nuevo Mundo, se extendió a los pueblos no-europeos a partir de comerciar con esclavos africanos a mediados del siglo XVI.

Para el tema que aquí tratamos, la cuestión primordial radica en comprender cómo dicho imaginario racista llegó a extenderse, incluso, a los que ya estaban considerados como "personas con el Dios equivocado" a finales del siglo XV. Puesto que las relaciones de los imperios europeos con los sultanatos islámicos pasaron de ser una relación "imperial" a ser una "relación colonial" (la erradicación española de Al-Andalus a finales del siglo XV y la posterior dominación de los moriscos en el siglo XVI; la colonización holandesa en Indonesia en el siglo XVII; la colonización británica de la India en el siglo XVIII; la colonización británica y francesa en Oriente Medio en el siglo XIX; y la desaparición y posterior reparto del Imperio Otomano entre varios imperios europeos al final de la Primera Guerra Mundial), los "pueblos con el Dios equivocado" del imaginario teológico cristiano de finales del siglo XV terminaron degradándose hasta la categoría de "animales" en los siglos XVI y XVII (Perceval, 1992 y 1997). Más tarde, esa base racial teológica se secularizó en un imaginario "evolucionista cientificista entre jeraquías de civilización" transformando a las "personas con la religión equivocada" de finales del siglo XV (contradicción interimperial) en la categoría inferior de "salvajes y primitivos" propia de las "personas sin civilización" (contradicción colonial) en el siglo XIX. Este proceso muestra una transformación crucial que va desde la inferiorización de las religiones no cristianas (como el islam, el judaísmo, etc.) a la inferiorización de los seres humanos que practican esas religiones (de ese modo los musulmanes y los judíos se convirtieron en semitas, es decir, una raza inferior para los europeos, perdiendo significado como identidad estrictamente religiosa). Esta mutación discursiva fue esencial 
para entretejer la inferiorización de la religión con el racismo contra los seres humanos no-europeos que practicaban esas religiones. La jerarquía global religiosa cristiano-céntrica y la jerarquía global euro-céntrica étnica/racial se entrelazaron de manera progresiva y la distinción entre la práctica de una religión no cristiana y el ser racializado como un ser humano inferior fue haciéndose poco a poco menos evidente. Pasaron de "pueblos con el Dios equivocado" a "pueblos que le rezan al Dios equivocado por ser racialmente inferiores".

\section{LA ISLAMOFOBIA COMO UNA FORMA DE RACISMO CULTURAL}

En los últimos 60 años se ha dado una transformación histórica en los discursos racistas, pues, mientras éstos han disminuido, el racismo cultural se ha convertido en un recurso hegemónico para el sistema-mundo (Grosfoguel, 2003). La derrota de la Alemania nazi, las luchas anticoloniales y los movimientos de derechos civiles de las minorías coloniales dentro de los imperios occidentales (estadounidense y británico, sobre todo), crearon las condiciones históricas y políticas para la transición del racismo biológico hacia el racismo cultural. Lo ocurrido fue que las élites blancas del sistema-mundo derrotadas por estos movimientos no renunciaron a su racismo, sino más bien, ingeniaron nuevas formas de dominación $\mathrm{racial} /$ colonial. El viejo discurso racista biológico al ser políticamente derrotado es reemplazado por el nuevo discurso racista culturalista. En este tipo de racismo cultural, la palabra raza no se menciona. Por lo general, el racismo cultural enfoca su atención en la inferioridad de las costumbres, las creencias, el comportamiento o los valores de un determinado grupo de personas. Se encuentra cercano al racismo biológico en el sentido de que éste naturaliza/esencializa la cultura de los pueblos racializados/inferiorizados, tipificados como invariables en un espacio atemporal.

En los nuevos discursos racistas culturales, la religión tiene un papel dominante. Los tropos contemporáneos sobre los "pueblos inferiores", "incivilizados", "bárbaros", "salvajes", "primitivos", "subdesarrollados", "autoritarios" y "terroristas" se fusionan hoy en las prácticas y creencias religiosas del otro. Al centrarse en la religión del otro, los europeos, los euro-americanos y los euro-israelíes escapan de ser acusados de racistas. Recordemos que al hacerse políticamente incorrecto el uso de discursos racistas biológicos a causa de su derrota política ante la lucha de los pue- 
blos coloniales, se acude al uso de argumentaciones racistas culturalistas donde la palabra raza no aparece. Sin embargo, cuando se analiza cuidadosamente la retórica hegemónica racista culturalista in situ, los tropos son una repetición de los viejos debates racistas biológicos y las personas que son las víctimas de los nuevos discursos racistas culturalistas son los tradicionales súbditos coloniales de los imperios occidentales, es decir, los "sospechosos de siempre".

Únicamente desde una perspectiva que tome en cuenta la imbricación entre las estructuras socio-históricas de larga duración del sistema-mundo y la reciente hegemonía del racismo cultural, se podrá entender la relación entre la islamofobia y el racismo. Es absolutamente imposible desvincular el odio o el miedo a los musulmanes del racismo contra el no-europeo que data del siglo XVI. Los discursos islamófobos y el racismo culturalista se entremezclan y se superponen. La asociación de los musulmanes con los súbditos coloniales de los imperios occidentales tiene una larga duración en el "sistema-mundo occidentalocéntrico/cristianocéntrico moderno/colonial capitalista/patriarcal" en las mentes y el imaginario de las poblaciones blancas europeas y norteamericanas. Esto produce una imbricación de la islamofobia con el racismo colonial que aún permanece viva en el mundo actual, especialmente en los centros metropolitanos, a pesar de la desaparición de las administraciones coloniales en casi todo el mundo desde hace 40 años.

En Gran Bretaña, los musulmanes son asociados a los egipcios, paquistaníes y bengalíes (súbditos coloniales de las antiguas colonias británicas). Mientras que la islamofobia se asocia al racismo contra los negros, los árabes y los asiáticos. Lo mismo sucede en Francia: los musulmanes proceden en su mayoría de África (de las antiguas colonias como Argelia, Marruecos, Túnez, Senegal, etc.). En Holanda, son en gran parte trabajadores inmigrantes y exsúbditos coloniales procedentes de Turquía, Marruecos, Indonesia y Surinam. La islamofobia en Holanda está asociada al racismo contra los trabajadores inmigrantes y antiguos súbditos coloniales. De manera que, si se entiende como el miedo o el odio a los musulmanes, se asocia a los racismos contra el árabe, el asiático y el negro. En el caso de Alemania, el islam se relaciona con el racismo contra los turcos, y en España la comparación es con el viejo racismo contra los moros. Del mismo modo, en Estados Unidos el islam se vincula con los afro-americanos y los árabes de todas las diferentes nacionalidades. Los puertorriqueños como 
súbditos coloniales del imperio de Estados Unidos también son sujetos sospechosos de la histeria islamofóbica. ${ }^{2}$ Los latinos son una población en crecimiento con el mayor número de conversos al islam. Esto, en Estados Unidos los convierte también en objetivo de las políticas neofascistas del gobierno norteamericano. Además, después del 11-S el Estado norteamericano relacionó a los inmigrantes ilegales con el terrorismo y, a nombre de la "seguridad nacional", condujo a incrementar la militarización de la frontera entre México y Estados Unidos.

Independientemente de que el sistema estatal de los Estados occidentales tenga como política interna el modelo multicultural británico o el modelo republicano francés, la realidad es que ninguno de los dos es funcional. De no superarse el problema de la discriminación racial, éste se convertirá en un proceso corrosivo que acabará destruyendo los ideales abstractos de cualquier modelo. En el caso del mundo angloamericano, el multiculturalismo y la diversidad intervienen para ocultar la supremacía blanca. A las minorías raciales se les permite celebrar su historia, sus fiestas y su identidad, siempre que dejen intacto el statu quo de la jerarquía étno/racial de supremacía blanca. El sistema dominante en el Reino Unido, Canadá y los Estados Unidos es una "acción afirmativa blanca" (discriminación positiva) institucionalizada y oculta los beneficios y privilegios concedidos a los blancos de forma cotidiana en todos los ámbitos de la existencia social. Es tan poderosa que se ha llegado a normalizar hasta el punto de no ser declarada como tal, es decir, como discriminación positiva para los blancos.

En el modelo republicano francés, el sistema formal de la igualdad actúa como un "comunitarismo masculino blanco" normalizado e institucionalizado. Si las minorías raciales, de género o de sexualidad protestan contra la discriminación, son acusadas por los "comunitaristas masculinos blancos" con base en el poder de actuar como "comunitaristas" (personas que reclaman derechos de manera egoísta solamente para su propio grupo

${ }^{2}$ Véase el caso de José Padilla, un puertorriqueño de Chicago que ha pasado más de tres años en una prisión militar incomunicado, sin cargo alguno. A pesar de que los puertorriqueños son ciudadanos de Estados Unidos, la neofascista Ley Patriótica estadounidense permite el encarcelamiento de ciudadanos de Estados Unidos sin límite, sin cargos legales ni procedimientos en un tribunal civil. La acusación pública inicial contra Padilla, realizada por las autoridades de Estados Unidos en el momento de su detención, fue la de que supuestamente tenía un documento para construir una bomba atómica doméstica en su apartamento de Chicago. La acusación es tan ridícula que lo mantuvieron en prisión sin un debido proceso en los tribunales durante varios años. 
sin tomar en cuenta a los demás). Es como si las élites fueran imparciales y neutrales frente a la discriminación racial y de género. Particularmente, la lógica de las élites blancas francesas está basada en el "principio universalista abstracto de igualdad”. La supremacía blanca en Francia funciona con el mito de una sociedad de igualdad imparcial que es "racialmente ciega" donde no se nombra la palabra raza. En Francia, el racismo "racialmente ciego" se ha institucionalizado y regularizado hasta el punto de invisibilizar la discriminación "comunitarista masculina blanca" presente en el poder.

Un ejemplo de este racismo culturalista es la islamofobia. La llamada "neutralidad" de Occidente se pone en entredicho cuando los musulmanes reclaman sus prácticas e identidades en la esfera pública o cuando entablan demandas contra la discriminación dentro del ámbito escolar o bien laboral, en pro de sus derechos dentro de los Estados occidentales. En Francia, la ley contra el uso del velo de las mujeres musulmanas en instituciones públicas, el encarcelamiento sin un debido proceso, y la tortura de miles de musulmanes en Estados Unidos son casos recientes de una larga lista de agravios.

A nivel mundial, la islamofobia es el discurso dominante utilizado dentro del actual contexto "poscolonial" y "posderechos civiles", donde ya no es "políticamente correcto" usar los viejos argumentos racistas biológicos. Ahora, los discursos racistas dominantes son culturalistas religiosos enfocándose en la islamofobia como la forma principal de golpear a los árabes. Los atentados del 11 de septiembre aumentaron el racismo contra los árabes a través de una histeria islamófoba en el mundo, particularmente entre las élites imperialistas-sionistas dominantes en Estados Unidos, Europa e Israel. Esto último no debería sorprender dada la manera en cómo estos países, incluso décadas antes del 11-S, estereotipan a palestinos, árabes y musulmanes como terroristas (Said, 1981).

La responsabilidad de la política exterior de Estados Unidos nunca se relaciona a los trágicos acontecimientos del 11-S. Es así como la guerra fría de ese país contra el "imperio del mal” en Afganistán durante la década de los ochenta financió, apoyó y creó una red mundial de grupos fundamentalistas terroristas islámicos llamada en ese momento Freedom Fighters ("combatientes por la libertad"), los cuales se constituyen en lo que hoy se conoce como Al-Qaeda, cuya operatividad tiene estrecha vinculación con las agencias de inteligencia occidentales (Chalmers, 2006). Estados 
Unidos actuó en complicidad con Osama Bin Laden e incluso participó en operaciones de Al-Qaeda como parte de los planes globales/imperiales de la CIA y las operaciones contra la Unión Soviética en la década de los ochenta. Sin embargo, es más fácil culpar a los árabes y utilizar argumentos racistas islamófobos que examinar críticamente la política exterior de Estados Unidos durante los últimos 50 años. Lo mismo se puede aplicar a Saddam Husein, quien fue un leal aliado de Estados Unidos e hizo su trabajo en una guerra sucia patrocinada por la CIA contra Irán. Siguió los planes globales/imperiales de Estados Unidos durante la década aludida pero más tarde fue declarado enemigo de ese mismo país; fue acusado falsamente por las élites estadounidenses de tener vínculos con Al-Qaeda con el fin de justificar una guerra planeada anticipadamente contra Iraq (Risen, 2006).

Es sintomático que en la mayor parte de los países occidentales, los árabes sigan siendo percibidos como si fueran "la mayoría musulmana en el mundo", aunque sólo constituyan una quinta parte de la población musulmana total en el mundo. Esto se relaciona con los planes globales/ imperiales occidentales para la dominación y la explotación del petróleo en el Medio Oriente y la resistencia de los árabes ante ello. La continua imagen exagerada que hace de los árabes sujetos terroristas y violentos en los medios de comunicación occidentales (periódicos, películas, radio, televisión, etc.), ha sido fundamental en la nueva ola de racismo islamófobo y, por supuesto, tiene raíces en un racismo culturalista que precede al 11-S (Said, 1981). No es casual que el objeto del racismo islamófobo en Occidente no sea sólo contra los árabes, sino que se extienda a los musulmanes del sur de Asia y de origen africano que ahí residen, viviendo las consecuencias de ese racismo contra los árabes especialmente en Estados Unidos y Francia (Salaita, 2006).

\section{LA ISLAMOFOBIA COMO ORIENTALISMO}

Uno de los argumentos culturales racistas utilizados hoy día contra los musulmanes es el "abuso patriarcal y sexista de la mujer". Como parte de la concepción del pueblo islámico como "inferior" en relación a Occidente, un argumento importante para sostener sus "incivilizados" y "violentos" valores/comportamientos, es la opresión de las mujeres a manos de los hombres. Resulta irónico escuchar al Occidente patriarcal y a personajes 
fundamentalistas y conservadores cristianos, referirse al feminismo como si fueran sus defensores cuando hablan sobre el islam. El argumento principal de George W. Bush para justificar la invasión a Afganistán fue la necesidad de liberar a la mujer "de color" de las atrocidades de los hombres "de color". La hipocresía del argumento es clara cuando vemos que el gobierno de Bush defendió activamente el fundamentalismo patriarcal cristiano, oponiéndose al aborto y a los derechos civiles y sociales de la mujer durante años en Estados Unidos, mientras paralelamente empleaba el argumento de los derechos de las mujeres contra los talibanes para invadir Afganistán. La retórica de "los hombres blancos como salvadores de las mujeres de color de los abusos patriarcales de los hombres de color" se remonta a la época colonial. Esto ha servido históricamente para ocultar las verdaderas razones de la colonización de los hombres blancos sobre el mundo no-occidental. Ahora sabemos que la invasión de Afganistán se dio por su ubicación geopolítica estratégica y su importancia en términos de proximidad al petróleo y al gas en el sur de Asia. Inmediatamente después de la invasión, el Afganistán ocupado proporcionó permiso legal a las compañías transnacionales de gas y petróleo para construir oleoductos en su territorio (Rashid, 2001). Las representaciones islamófobas que ven a los musulmanes como salvajes que necesitan de las misiones "civilizadoras occidentales" es el principal argumento para encubrir los planes militares y económicos globales/imperiales.

Por otra parte, la colonización del islam por el patriarcado no es algo exclusivo de él, pues se pueden ver los mismos abusos contra la mujer entre los hombres cristianos (católicos y protestantes). Existen muchos razonamientos patriarcales y sexistas tanto en los pueblos cristianos como en los musulmanes o judíos. Sin embargo, la caracterización sexista y patriarcal del islam es lo que aparece en la prensa, mientras tanto se silencia la opresión de las mujeres en Occidente. Es importante decir que el islam fue la primera religión en el mundo que reconoció a las mujeres el derecho al divorcio hace más de mil años. El mundo cristiano lo hizo muy recientemente, a finales del siglo XX - la Iglesia católica y muchos países aún no lo reconocían-. Decimos esto no para justificar los abusos patriarcales sobre la mujer realizados por algunos musulmanes, sino para cuestionar la representación racial estereotipada que hace sólo de los hombres musulmanes el foco de los abusos contra las mujeres en el mundo. Este argumento islamófobo es incoherente, inconsistente y falso. Sólo sirve a los 
propósitos occidentales globales/imperiales. Lamentablemente, algunas feministas occidentalo-céntricas han hecho eco de estas representaciones imperialistas y racistas.

Por lo tanto, lo que tenemos en el mundo de hoy no es un choque de civilizaciones sino un choque de fundamentalismos (Tariq, 2002) y patriarcados. La administración Bush defendió los argumentos fundamentalistas cristianos para caracterizar al "enemigo islámico" como parte de las Cruzadas de la antigüedad, mientras que los fundamentalistas islámicos utilizan un lenguaje similar. ${ }^{3}$ Por su parte, el fundamentalismo cristiano defiende un modelo occidental de patriarcado con la familia monógama en su centro, en nombre de la civilización y el progreso; mientras que el fundamentalismo islámico defiende formas no-occidentales de patriarcado con la poligamia para los hombres (no para las mujeres) autorizada como elemento nodal de la estructura familiar. Empero, algunas feministas islámicas han sostenido que las versiones patriarcales del islam no son inherentemente islámicas, sino que representan su colonización por el patriarcado (Mernissi, 1987). La interpretación de las escrituras sagradas originales fue secuestrada por los hombres durante toda la historia del islam.

Lo mismo podría decirse de los textos sagrados judíos y cristianos, pues fueron monopolizados por interpretaciones patriarcales de las escrituras sagradas como perspectiva dominante de esas religiones. Por lo tanto, no existe un "patriarcado" como un sistema único, sino más bien, "patriarcados" en el sentido de varios modos de dominación de género de los hombres sobre las mujeres. El patriarcalismo que se ha globalizado actualmente en el sistema-mundo es la forma judeo-cristiana occidental de patriarcado. Los modelos no occidentales de patriarcado han coexistido con Occidente en las regiones periféricas del sistema-mundo, y en muchas épocas de la historia colonial occidental fue cómplice de ellos en sus proyectos coloniales/imperiales. Hablar como si el patriarcado fuera externo a Occidente y localizado en el islam es una distorsión orientalista de la historia que se remonta a las representaciones eurocéntricas del islam hechas en el siglo

3 Habría que aclarar aquí que no todo islam político es fundamentalista, como nos hacen creer los discursos imperialistas-sionistas occidentales. El fundamentalismo es una forma de islam político que tiene raíces profundas en el wahabismo. Este último es el islam que se practica en Arabia Saudita (país aliado de Occidente) y que ha sido propagado por el mundo con el apoyo y financiamiento de las agencias de inteligencia occidentales. 
XVIII. La expansión colonial europea ha exportado por el mundo no sólo capital y militarismo, sino también patriarcados.

Es importante tener en cuenta que las opiniones de los orientalistas se han caracterizado por imágenes del islam exóticas, racistas y esencialistas, como si los musulmanes fueran pueblos sin historia y el islam una cultura congelada en el tiempo (Said, 1979). Estas representaciones orientalistas del islam después del siglo XVIII, fueron precedidas por 300 años de occidentalismo (la superioridad de Occidente sobre el resto) desde finales del siglo XV hasta la aparición del orientalismo en el siglo XVIII. La condición de posibilidad histórica y política del surgimiento del orientalismo es el occidentalismo.

\section{LA ISLAMOFOBIA COMO RACISMO EPISTEMOLÓGICO}

El occidentalismo creó el privilegio epistémico y la política de identidad hegemónica de Occidente desde la cual se juzga y produce el conocimiento acerca del otro. La ego-política del conocimiento de René Descartes en el siglo XVII, donde los hombres occidentales sustituyen a Dios como fundamento del conocimiento, es la base fundacional de la filosofía occidental moderna. Sin embargo, como nos recuerda Enrique Dussel (1994), filósofo latinoamericano de la liberación, el ego-cogito de Descartes ("Pienso, luego existo") fue precedido por 150 años del ego-conquiro ("Conquisto, luego existo"). La perspectiva del "ojo de Dios" defendida por Descartes transfirió los atributos del Dios cristiano a los hombres occidentales (el género aquí no es accidental). Pero, eso sólo era posible desde un ser imperial, es decir, desde la subjetividad y existencia de alguien que está en el centro del mundo porque lo ha conquistado.

El mito sobre la capacidad de los hombres occidentales para producir un conocimiento que es universal más allá del tiempo y el espacio es fundamental para los diseños imperiales/globales. La ego-política cartesiana del conocimiento inauguró lo que el filósofo colombiano Santiago Castro-Gómez llamó la "epistemología del punto cero". Esta perspectiva reproduce el mito occidental acerca de un punto de vista que no le asume como tal, pues este mito ha permitido a los hombres occidentales declarar que su conocimiento es universal, neutro y objetivo. Autores contemporáneos como Samuel Huntington (1997) repiten una combinación del viejo occidentalismo y orientalismo. Se da por descartada la superioridad de Occidente y el pri- 
vilegio epistemológico de la política de identidad occidental desde la que se generan juicios sobre el otro, junto a los diseños globales/imperiales constituyentes de una premisa indiscutible.

¿Cuál es la relevancia de este debate epistemológico para la islamofobia? Es a partir de una política de identidad hegemónica occidental y de privilegio epistémico eurocéntrico desde la que el resto de las epistemologías y cosmologías del mundo se inferiorizan por medio de caracterizarlas como mito, religión, folclor o cultura, degradando el conocimiento no-occidental por debajo de las categorías de filosofía y ciencia. Justo aquí se da este emplazamiento epistémico hegemónico desde donde los pensadores occidentales producen el orientalismo acerca del islam. El primero conduce al racismo epistemológico, es decir, a la inferiorización y subalternización del conocimiento no occidental, mientras que el segundo conduce al orientalismo, a la clasificación y cosificación del otro. La subalternización y la inferiorización del islam no constituían sólo una degradación como espiritualidad, sino también como epistemología.

Los pensadores críticos musulmanes son considerados "inferiores" frente a los pensadores cristianos y seculares occidentales. La superioridad de la epistemología occidental permite construir con autoridad la imagen del otro musulmán, como personas y culturas inferiores congeladas en el tiempo. El racismo epistemológico conduce a la orientalización del islam y permite a Occidente no tener que escuchar el pensamiento crítico producido por los pensadores islámicos sobre los diseños globales/imperiales occidentales. Esto es crucial porque la islamofobia como forma de racismo no es exclusivamente un fenómeno social, sino también una cuestión epistemológica: el racismo epistemológico. El pensamiento que viene de lugares no-occidentales no es considerado digno de atención, salvo para mostrarlo como "incivilizado", "primitivo", "bárbaro" y "atrasado". El racismo epistemológico permite a Occidente decidir unilateralmente qué es lo mejor para los musulmanes de hoy, y obstruir cualquier posibilidad de un diálogo intercultural serio. La islamofobia como forma de racismo contra los musulmanes no sólo se manifiesta en el mercado laboral, la educación, la esfera pública, la guerra global contra el terrorismo o la economía mundial, sino también en el campo de batalla epistemológico por la definición de las prioridades y de la institucionalidad del mundo.

Acontecimientos como el ataque del 11-S en Estados Unidos, los disturbios en los "suburbios" de París en noviembre del 2005, la xenofobia 
contra los inmigrantes, las manifestaciones contra las caricaturas danesas del profeta Mahoma, el atentado en las estaciones de metro en Londres, el triunfo de Hamas en la elecciones palestinas, la resistencia de Hezbolá a la invasión israelí del Líbano, el atentado en los trenes de cercanías en España (11-M) y el conflicto de la energía nuclear con Irán, han sido todos codificados en un lenguaje islamófobo en la esfera pública occidental. Tanto políticos occidentales como los principales medios de comunicación fueron participantes activos de las reacciones islamófobas ante los acontecimientos descritos.

El racismo epistemológico contribuye a legitimar una artillería de expertos, asesores, especialistas, funcionarios, académicos y teólogos que siguen hablando con autoridad sobre el islam y los musulmanes, a pesar de su absoluta ignorancia sobre el tema y sus prejuicios islamófobos. Dicha artillería de intelectuales productores del conocimiento orientalista sobre la inferioridad del islam y su gente se ha venido sucediendo desde el siglo XVI en España (Perceval, 1992) y el siglo XVIII en Francia e Inglaterra (Said, 1979), contribuyendo al rechazo arrogante occidental de los pensadores musulmanes.

El racismo y el sexismo epistémicos son las formas de racismo y sexismo más veladas en el "sistema mundo capitalista/patriarcal moderno/ colonial occidentalizado/cristianizado" (Grosfoguel, 2008) que todos habitamos. Los racismos y sexismos sociales, políticos y económicos son mucho más visibles y reconocidos hoy en día que el racismo/sexismo epistemológico. No obstante, el racismo epistémico es fundacional, o sea, la versión más antigua del racismo en cuanto supone la inferioridad de los "no-occidentales" como seres inferiores (no humanos o subhumanos). Esto se define con base en su cercanía a la animalidad y considerando una inteligencia inferior; por ende, se alude a la falta de racionalidad. Asimismo, funciona a través de los privilegios de una política esencialista ("identitaria") de las élites masculinas "occidentales"; es decir, la tradición de pensamiento hegemónica de la filosofía occidental y la teoría social que rara vez incluye a las mujeres "occidentales" y nunca incorpora a los/ las filósofos/as, las filosofías y científicos/as sociales "no-occidentales". En este pensamiento racista/patriarcal, se considera a Occidente capaz de producir conocimiento y como la única con acceso a la "universalidad", la "racionalidad" y la "verdad". El racismo/sexismo epistémico concibe el conocimiento "no-occidental" como inferior al "occidental", dado que el 
racismo epistémico está involucrado con el patriarcado judeo-cristiano y su sexismo epistémico, privilegiando el conocimiento masculino "occidental" como superior en el mundo actual.

Si tomamos el canon de pensadores privilegiados en las disciplinas académicas occidentales, podemos observar que otorgan prioridad - sin excepción-a los autores y teorías masculinas “occidentales", específicamente las de los europeos y euronorteamericanos. Es tan poderosa y normalizada esta "política identitaria" hegemónica esencialista - mediante el discurso de "objetividad" y "neutralidad" de la "ego-política del conocimiento" cartesiano en las ciencias sociales-, que es capaz de disimular quién habla $y$, situados en las relaciones de poder, cuestionar qué posición ocupa. De modo que, cuando pensamos o acusamos a alguien por utilizar el "esencialismo identitario o de política identitaria" (identity politics), de inmediato asumimos por "sentido común" que estamos hablando de minorías racializadas. De hecho, sin negar la existencia de "políticas identitarias" esencialistas entre algunas minorías racializadas, la "política identitaria" hegemónica - la del discurso masculino eurocéntrico - las usa para desechar toda intervención crítica enraizada en epistemologías y cosmologías provenientes de grupos oprimidos y tradiciones de pensamiento "no-occidentales" (Maldonado, 2008). El mito subyacente de la academia occidentalizada sigue siendo el argumento cientificista de la "objetividad" y la "neutralidad" que oculta el "locus de enunciación" del hablante. Es decir, quién habla y desde qué corpo-política del conocimiento, y qué geopolítica del conocimiento enuncian las relaciones de poder existentes a escala mundial. A través del mito de la "ego-política del conocimiento" (que en realidad habla siempre a través de un cuerpo masculino "occidental" y de una geopolítica del conocimiento eurocéntrica), se niegan y desechan por particularistas las voces y los pensamientos críticos provenientes de personas y grupos inferiorizados y subalternizados por este racismo epistémico/sexista/hegemónico. Si la epistemología tiene color -como también lo señala el filósofo africano Emmanuel Chukwudi Eze (1997) - y género/color - como lo ha argumentado la socióloga afro-estadounidense Patricia Hills Collins (1991) - entonces dicha epistemología eurocéntrica que domina las ciencias sociales tiene color y género. La construcción que de ello hacen los hombres "occidentales", considerándole superior en comparación con el resto del mundo, es inherente al racismo/sexismo epistemológico, prevaleciente en el sistema-mundo durante más de 500 años. 
El privilegio epistémico de Occidente se consagró y normalizó con la destrucción de Al-Andalus por la monarquía católica española y con la expansión colonial europea desde finales del siglo XV. Desde la redefinición y nombramiento del mundo con la cosmología cristiana (por ejemplo, uso de nombres como Europa, África, Asia y, más tarde, América) y la caracterización de todo el conocimiento no cristiano como producto de fuerzas paganas y diabólicas, hasta la presunción en su provincialismo eurocéntrico de que es sólo en la tradición grecorromana, pasando por el Renacimiento, la Ilustración y las ciencias occidentales, se alcanza la "verdad" y la "universalidad", se normalizó el privilegio epistémico de la "política identitaria" masculina, occidental y eurocéntrica hasta el punto de la invisibilidad como "política identitaria" hegemónica. Se convirtió en el conocimiento universal normalizado. De esta manera, se consideraron inferiores todas las "otras" tradiciones de pensamiento (caracterizadas en el siglo XVI como "bárbaras", en el XIX como "primitivas", en el XX como "subdesarrolladas", y a comienzos del XXI como "antidemocráticas"). Así, desde la formación de las "ciencias sociales liberales occidentales", en el siglo XIX el racismo y sexismo epistémicos han sido constitutivos de sus disciplinas y de la producción de conocimiento. Las ciencias sociales occidentales asumen la inferioridad, parcialidad y falta de objetividad en su producción del conocimiento "no-occidental", al mismo tiempo que asumen la superioridad del conocimiento occidental. Como resultado de ello, la teoría social occidental se basa en la experiencia histórico-social de cinco países (Francia, Inglaterra, Alemania, Italia y Estados Unidos) que constituyen no más del $12 \%$ de la población mundial. Los teóricos que componen el canon de las disciplinas de las ciencias occidentales provienen fundamentalmente de estos cinco países. El provincialismo de la teoría social respecto de la ciencia social occidental con falsas pretensiones de universalidad, pretende que la base de la experiencia socio-histórica sea teorizada por hombres de estos países, y además dé cuenta del $88 \%$ restante de la población mundial. Si agregamos que la teoría social producida a partir de la experiencia social en estos cinco países es masculina, ignorando las aportaciones teóricas de la mujer, entonces, el provincialismo es todavía mayor, pues la teoría social es representativa de la experiencia histórico-social del 6\% de la población mundial. En suma, el eurocentrismo, con su racismo/sexismo epistémico, es una forma de provincialismo camuflajeado de universalismo reproducido en las ciencias sociales hoy. 
Contra esta "política identitaria" hegemónica que siempre privilegió la belleza, el conocimiento, las tradiciones, las espiritualidades y cosmologías masculina, cristiana y occidental, a la vez que consideraba inferiores y subalternas estas mismas, pero de carácter no cristiano ni occidental, aquellos sujetos representados como inferiores y subalternos por dichos discursos hegemónicos desarrollaron su propia "política identitaria” en reacción al racismo de los primeros. Este proceso es necesario como parte de una autovaloración en un mundo racista/sexista que los muestra como inferiores y descalifica su humanidad. Sin embargo, este proceso de afirmación identitaria tiene sus límites si conduce a planteamientos fundamentalistas que inviertan los términos binarios de la tradición hegemónica de pensamiento filosófico racista, sexista y eurocéntrico de los hombres occidentales. Por ejemplo, asumir que los grupos étnico-raciales no occidentales subalternos son superiores y los grupos dominantes étnico-raciales occidentales son inferiores, simplemente se están invirtiendo los términos del racismo occidental hegemónico sin superar su problema fundamental; es decir, el racismo que vuelve inferiores a algunos seres humanos y eleva categorialmente a otros con base en principios culturales o biológicos (Grosfoguel, 2003). Aquí no se estarían desplazando los binarios del pensamiento eurocéntrico sino que se afirmarían por la vía de la inversión. Otro ejemplo es aceptar — como lo hacen algunos fundamentalistas islámicos y afrocéntricos - los discursos eurocéntricos fundamentalistas hegemónicos que consideran la tradición europea como la única natural e inherentemente democrática, mientras se pretende que los otros (no europeos) son natural e inherentemente autoritarios, negando al mundo no occidental discursos democráticos y formas de democracia institucional (que, por supuesto, son distintos de la democracia liberal occidental); y como resultado, terminan apoyando formas políticas autoritarias. Esto hacen todos los fundamentalistas del Tercer Mundo cuando aceptan la falsa premisa fundamentalista eurocéntrica de que la única tradición democrática es la occidental y, por consiguiente, asumir que la democracia no se aplica a su "cultura" y "sociedades", defendiendo formas monárquicas, autoritarias o dictatoriales de autoridad política. Esto no hace más que reproducir una forma invertida de esencialismo eurocéntrico. La idea de que la "democracia" es inherentemente "occidental" y las formas "no democráticas" son "no-occidentales" es compartida tanto por los discursos fundamentalistas eurocéntricos hegemónicos como por sus variaciones, tales como 
los fundamentalismos "tercermundistas". Las "divisiones" que resultan de estas políticas identitarias terminan por reproducir a la inversa el mismo esencialismo y fundamentalismo del discurso eurocéntrico hegemónico. Si definimos el fundamentalismo como aquellas perspectivas que dan por hecho que su cosmología y su epistemología son superiores y únicas fuentes de verdad, inferiorizando y negando la igualdad a otras, entonces el eurocentrismo es el fundamentalismo más importante del mundo actual. Esos fundamentalismos tercermundistas (afrocéntricos, islámicos, indigenistas, etc.) surgidos en respuesta al eurocéntrico hegemónico y que la prensa "occidental" exagera todos los días en las primeras planas de los periódicos, son formas subordinadas del fundamentalismo eurocéntrico en la medida que reproducen y dejan intactas las jerarquías raciales, binarias y esencialistas del fundamentalismo eurocéntrico hegemónico (Grosfoguel, 2009). Se han normalizado a tal punto que nunca vemos en las primeras planas de los periódicos un titular que diga: "El fundamentalismo eurocéntrico con su terrorismo de Estado ha asesinado a más de un millón de civiles en Iraq". En suma, una consecuencia política de esta discusión epistemológica es que una base fundacional en las discusiones actuales sobre el islam político - sobre el significado de "democracia"-, y en la llamada "guerra contra el terrorismo", es el "racismo/sexismo epistémico". Cuando éste inferioriza las epistemologías y cosmologías "no-occidentales" privilegiando la de los hombres "occidentales" como forma superior de conocimiento y como único cimiento para definir los derechos humanos, la democracia, la justicia, la ciudadanía, etcétera, termina descalificando al "no-occidental" al considerarlo incapaz de producir estos derechos. Dicha concepción se basa en la idea esencialista de que la razón y la filosofía radican en "Occidente", mientras que el pensamiento no racional radica en el "resto".

\section{LA ISLAMOFOBIA COMO RACISMO EPISTÉMICO EN LA TEORÍA SOCIAL}

El racismo epistémico en su dimensión de islamofobia epistémica constituye una lógica fundacional y constitutiva del mundo moderno/colonial y de sus legítimas formas de producción de conocimiento. Desde el siglo XVI, los humanistas y académicos europeos han sostenido que el conocimiento islámico es inferior al occidental. Así, el debate sobre los moriscos en el siglo XVI en España estaba lleno de concepciones epistémicas islamofóbi- 
cas (Perceval, 1992 y 1997). Después de su expulsión a comienzos del siglo XVII, prosiguió la inferiorización de los "moros" bajo un discurso epistémico islamofóbico. En el siglo XIX, influyentes pensadores europeos, como por ejemplo Ernest Renan, sostenían que "el islam era incompatible con la ciencia y la filosofía" (Renan, 2003).

De manera similar, en las ciencias sociales tenemos manifestaciones concretas de la islamofobia epistémica en la obra de teorías sociales clásicas de la ciencia social patriarcal occidentalo-céntrica, como las de Karl Marx y Max Weber. Sukidi, (2006), señala al respecto:

El islam, según Weber, era el polo opuesto del calvinismo. No había dos caras de la moneda en la predestinación en el islam. En lugar de ello, como lo aseveró Weber en su Ética Protestante (cap. 4, n. 36), el islam contiene una creencia en la predeterminación, no en la predestinación, que se refería al destino de los musulmanes en este mundo, no en el siguiente (p. 185). La doctrina de la predestinación que defendían los calvinistas, y que los llevó al trabajo duro como un deber (vocación, llamado), no es evidente entre los musulmanes. De hecho, como lo afirmaba Weber, "lo más importante, la prueba del creyente en la predestinación, no tenía papel alguno en el islam". Sin el concepto de la predestinación, el islam no podía ofrecer a sus creyentes una actitud positiva hacia esta actividad mundana. En consecuencia, los musulmanes están condenados al fatalismo (2006: 197).

Las racionalizaciones de la doctrina y la conducta de vida eran ajenas al islam. Weber usó la creencia en la predestinación como concepto clave para explicar la racionalización de la doctrina y la conducta de vida. En el calvinismo, la creencia en la predestinación podía desde luego generar un rigor ético, un legalismo y una conducta racional en esta actividad mundana. No había nada de esto en el islam (p. 199). En consecuencia, la creencia islámica en la predestinación no conducía a la racionalización de la doctrina y la conducta de vida. De hecho, convertía a los musulmanes en fatalistas irracionales. El "islam", en opinión de Weber, "se desviaba por completo de cualquier conducta de vida racional por la aparición del culto a los santos y finalmente por la magia" (2006: 200).

Si seguimos la lógica de Weber hasta sus consecuencias finales, esto es, que los musulmanes son irracionales y fatalistas, entonces ningún conocimiento serio puede venir de ellos. ¿Cuáles son las geopolíticas del conocimiento implicadas en el racismo epistémico weberiano sobre los pueblos musulmanes? La geopolítica del conocimiento es la islamofobia epistémica de los orientalistas franceses y alemanes que se repite en el veredicto sobre el islam dictado por Weber. Para él, únicamente 
la tradición cristiana da lugar al racionalismo económico y, con ello, al moderno capitalismo occidental. El islam no puede compararse con la "superioridad" de los valores occidentales en cuanto carece de ciencia, racionalidad e individualidad. La ciencia y su derivada, la tecnología racional, son - según Weber- desconocidas para las civilizaciones orientales, siendo afirmaciones bastante problemáticas. Estudios como los de Saliba (1997) y Graham (2006) han demostrado la influencia de los desarrollos científicos del mundo islámico en la ciencia y la filosofía modernas de Occidente. Sus avances en la astronomía, biología, matemáticas, física y filosofía fueron fundamentales para las ciencias modernas occidentales. De manera que la racionalidad era un precepto central de la civilización islámica. De hecho, los filósofos griegos llegan a Europa vía los filósofos musulmanes de la España islámica. Por siglos, mientras se estudiaba y profundizaba la filosofía griega en el mundo islámico, en la cristiandad la Inquisición castigaba a todo aquel que tuviera copia de un libro de Aristóteles. En la Edad Media, Europa estaba sumida en una superstición feudal oscurantista de la cristiandad y la Escuela de Bagdad (ciudad central de la civilización islámica) era uno de los centros del mundo en la producción y la creatividad científica e intelectual. Por ejemplo, la Escuela de Astronomía de Bagdad descubre cuatro siglos antes que Europa que la Tierra no es el centro del universo. Las opiniones sobre el islam de Weber y de los orientalistas weberianos reproducen una islamofobia epistémica según la cual los musulmanes son incapaces de producir ciencia y de tener racionalidad, pese a la evidencia histórica que afirma lo contrario.

El mismo problema de islamofobia epistémica lo encontramos en Marx y Engels. Aunque Marx pasó dos meses en Argel en 1882 recuperándose de una enfermedad, casi no escribió sobre el islam. Empero, tenía una visión epistémica orientalista racista de los pueblos no occidentales en general, que es desarrollada ampliamente en sus escritos (Moore, 1997). Más aún, su cercano colaborador, Frederick Engels, escribió sobre los musulmanes y repitió los estereotipos racistas que usó Marx contra los "orientales". Hablando sobre la colonización de Algeria por los franceses, Engels afirmó:

Por encima de todo es, en nuestra opinión, muy afortunado que haya caído el jeque árabe. La lucha de los beduinos no tenía esperanza, y aunque desde todo punto de vista censurable la manera en que brutales soldados, como Bugeaud, han conducido la guerra, la conquista de Algeria es un hecho importante y venturoso para el progreso de la civilización. La piratería de los estados bárbaros nunca impedida por el gobierno inglés siempre y 
cuando no afectara sus embarcaciones, no podía echarse abajo sino por la conquista de uno de dichos estados. Y la conquista de Algeria ya ha forzado a los beis de Túnez y Trípoli, e incluso al emperador de Marruecos, a asumir la vía de la civilización. Se les obligó a encontrar un empleo para sus gentes diferente de la piratería[...] Y si podemos lamentar la destrucción de la libertad de los beduinos del desierto, no debemos olvidar que esos mismos beduinos fueron un país de ladrones cuyos principales medios de vida consistían en hacer incursiones contra los demás, o contra los lugareños establecidos, tomando lo que encontraban, masacrando a quienes se resistían, y vendiendo como esclavos los prisioneros restantes. Todos estos países de bárbaros libres parecen muy orgullosos, nobles y gloriosos a distancia, pero no es sino acercarse a ellos para descubrir que, al igual que las naciones más civilizadas, están dominados por el afán de lucro, y sólo emplean los medios más rudos y crueles. Y después de todo, el burgués moderno, con la civilización, la industria, el orden, y por lo menos una relativa ilustración que lo completa, es preferible al ladrón merodeador feudal, con el bárbaro estado de la sociedad a la que pertenecen (Engels, 1848, citado en Avineri, 1968: 43).

La alternativa de Engels es bastante clara: apoyar la expansión colonial y mantener la civilización occidental aun cuando sea burguesa y brutal con el fin de superar un estado de cosas "bárbaro". La superioridad de "Occidente sobre el resto" y, en particular, sobre los musulmanes es muy evidente con esta afirmación. Hablando sobre India, el irracional fanatismo de los musulmanes se explica, según Engels, por "el conflicto armado insurgente [que] comienza ahora a tomar el cariz del de los beduinos de Algeria contra los franceses; con la diferencia de que los hindús están lejos de ser tan fanáticos y de que no son una nación de jinetes" (Engels, 1958).

Por si acaso queda alguna duda sobre las opiniones que compartían Marx y Engels sobre la inferioridad de los musulmanes y pueblos "no-occidentales", la siguiente cita de Marx la disipa:

La cuestión no es si los ingleses tenían derecho de conquistar la India, sino si vamos a preferir que la India sea conquistada por los turcos, los persas, los rusos, a que sea conquistada por los británicos. Inglaterra debe cumplir una doble misión en la India: una destructiva, la otra regeneradora -la aniquilación de la antigua sociedad asiática, y la colocación de los cimientos materiales de la sociedad occidental en Asia. Árabes, turcos, tártaros y mongoles, que invadieron sucesivamente la India, pronto se adhirieron al hinduismo, siendo los conquistadores bárbaros, por una eterna ley de la historia, conquistados por la civilización superior de sus sometidos. Los británicos fueron los primeros conquistadores con una civilización supe- 
rior y, por ende, inaccesible a la hindú. No está lejos el día en que por una combinación de líneas ferroviarias y barcos a vapor, se acorte la distancia entre Inglaterra y la India, en términos de tiempo, a ocho días, y en que el otrora fabuloso país se anexe así en forma real al mundo occidental (Marx, 1853: 81-83).

Marx no tenía fundadas esperanzas en el espíritu proletario de las masas musulmanas cuando afirmó lo siguiente en relación con la expansión del Imperio Otomano a los territorios de Europa del Este (a petición de Marx, la cita fue publicada con la firma de Engels):

El principal poder de la población turca en Europa, independientemente de ser una reserva siempre lista a ser traída de Asia, radica en el populacho de Constantinopla [Estambul] y otras pocas ciudades grandes. Es en esencia turca, y aunque halla su principal sostén realizando trabajos para cristianos capitalistas, mantiene con gran envidia la superioridad imaginaria y la impunidad real por los excesos que los privilegios del islam le confieren en comparación con los cristianos. Es bien sabido que en cada golpe de estado importante debe persuadirse a este populacho mediante sobornos y adulación. Es tan sólo este populacho, con excepción de unos pocos distritos colonizados, el que ofrece una masa compacta e imponente de población turca en Europa. Sin duda habrá, antes o después, una absoluta necesidad de liberar una de las mejores partes de este continente del dominio de este populacho, en comparación con la cual el populacho de la Roma imperial era una congregación de sabios y héroes (Engels, 1853, en Avineri, 1968: 54).

Para Marx, al igual que para Weber, los musulmanes de origen turco son una caterva de ignorantes que hacen parecer sabios al populacho del imperio romano. Al convocar una lucha de liberación contra los pueblos musulmanes, estaba haciendo referencia a la superioridad de la civilización occidental. Desde su perspectiva, es mejor la expansión colonial occidental que dejar intactos a unos bárbaros inferiores en un estadio intemporal e inferior de la humanidad.

Karl Marx recelaba de los musulmanes y estaba convencido de los rasgos intrínsecamente xenofóbicos que había en el islam, y por ello escribió de manera apologética sobre el colonialismo occidental. Desconociendo e inferiorizando la visión coránica, dijo:

Como el Corán trata a todos los extranjeros como enemigos, nadie osará presentarse en un país musulmán sin haber tomado sus precauciones. Los primeros mercaderes europeos, por consiguiente, que se arriesgaron a in- 
tentar el comercio con tales gentes, se las ingeniaron para asegurarse un tratamiento excepcional y privilegios originalmente personales, pero que después se extendieron a todo su país. De ahí el origen de las capitulaciones (Marx, 1854, en Avineri, 1968: 146).

Marx afirmó, repitiendo el racismo epistémico generalizado de la visión orientalista de su época, que:

El Corán y la legislación musulmana que de él emanaba reduce la geografía y la etnografía de los diversos pueblos a la simple y conveniente distinción de dos naciones y dos países; los de los Fieles y los de los Infieles. El Infiel es "harby", es decir, el enemigo. El islamismo proscribe la nación de los Infieles, creando un estado de hostilidad permanente entre el musulmán y el no creyente (Marx, 1854, en Avineri, 1968: 144).

Estas opiniones simplificadas, esencialistas y reduccionistas del islam desde una perspectiva judeo/cristiano-céntrica, occidentalo-céntrica, formaban parte del racismo epistémico y del paternalismo condescendiente de los orientalistas occidentales hacia el pensamiento islámico, en el cual Marx no era una excepción. En el mundo musulmán había más derechos reconocidos hacia las minorías judías y cristianas que en el de la cristiandad europea. Por siglos, los judíos tuvieron que escapar del genocidio de la Europa de la cristiandad y refugiarse en los países musulmanes donde los pueblos del Libro (judíos y cristianos) son tratados con todos los derechos, quedando totalmente ocultos en la visión racista y eurocéntrica del mundo. Marx creía que el secularismo era fundamental para que la revolución tuviera una oportunidad en tierras musulmanas. Así lo expresó:

Si abolimos su sujeción al Corán, mediante una emancipación civil, cancelamos al mismo tiempo su sujeción al clero, y provocamos una revolución en sus relaciones sociales, políticas y religiosas. Si se suplanta el Corán por un code civil, debe occidentalizarse toda la estructura de la sociedad bizantina (Marx, 1854, en Avineri, 1968: 146).

Esta visión secularista de Marx era una estrategia colonial típica promovida por los imperios occidentales para destruir las formas de pensamiento y vida de los sujetos coloniales e impedir cualquier asomo de resistencia. Argumentando que los musulmanes están sometidos al dominio de una "religión", Marx proyectó en el islam la cosmología de la visión secularizada occidentalo-céntrica y cristiano-céntrica. El islam no se considera a sí misma una "religión" en el sentido occidentalizado y 
cristianizado de una esfera separada de la política, la economía, etcétera. Se identifica más con una cosmología que sigue la noción de "Tawhid", una doctrina de unicidad dentro de la diversidad, una visión holística del mundo, que la visión dualista moderno/colonial eurocéntrica (que primero fue un dualismo cristiano y luego cartesiano) destruyó en Occidente (ver la matanza de millones de mujeres en Europa acusadas de brujas en el siglo XVI) y con su expansión colonial intentó colapsar en el resto del mundo. La visión holística como tendencia general no puso obstáculos al pensamiento crítico o a la ciencia, así como sucedió en la cristiandad. La práctica de la cristianización colonial a comienzos del periodo moderno/ colonial y el secularismo cientificista a partir del siglo XVIII eran parte del "epistemicidio" y "espiritualicidio", o sea, la exterminación de la espiritualidad y las formas de conocimiento no-occidentales por parte de la expansión colonial occidental. El "epistemicidio" y el "espiritualicidio" hicieron posible la colonización de mentes y cuerpos de los sujetos coloniales.

Las ciencias sociales occidentales están configuradas por prejuicios epistémicos eurocéntricos e islamofóbicos. Decolonizarlas implicaría muchos procesos importantes que no podemos explicar a detalle aquí. Pero uno de ellos sería ampliar el canon de la teoría social para incorporar como componente central las contribuciones de teóricos y científicos descoloniales europeos y no europeos, como Enrique Dussel, Boaventura de Sousa Santos, Salman Sayyid, Ali Shariati, Silvia Rivera Cusicanqui, W. E. B. Dubois, Silvia Wynter, Esteban Ticona y Angela Davis, entre otros, que piensan desde el lado colonizado e inferiorizado de la modernidad/ colonialidad. Incorporar estos pensadores no es cuestión de multiculturalismo, sino de crear una ciencia social descolonial más rigurosa y pluriversal (en oposición a la ciencia social occidentalo-céntrica y colonial con pretensiones de universalidad) (Grosfoguel, 2008). Ali Shariati, en particular, es un científico social islámico que produjo importantes críticas de teóricos sociales occidentales como Marx, y hasta la fecha ha sido ignorado.

Justo ahora, la nombrada ciencia social es una tradición de pensamiento masculina occidental muy particular y provincial. Para descolonizar las ciencias sociales provinciales occidentalizadas debemos pasar a un diálogo horizontal global inter-epistémico para refundarlas a manera descolonial y pluriversal, en lugar del actual modo universalista. Ésta no es 
una tarea fácil, sin embargo, es importante señalar que la transformación del universalismo hacia el pluriversalismo en las ciencias sociales es fundamental para pasar del marco en el que uno define (las ciencias sociales coloniales) a un nuevo paradigma donde la producción de conceptos y conocimiento es resultado de un verdadero diálogo inter-epistémico universal y horizontal (las ciencias sociales transmodernas pluriversales descoloniales) (Grosfoguel, 2007). Esto no es un llamado al relativismo, sino a pensar la universalidad como pluriversalidad, es decir, como resultado de la interacción y el diálogo inter-epistémico de modo horizontal.

La importancia de esta discusión sobre la islamofobia epistémica es que esta última se manifiesta con fuerza en los debates y las políticas públicas contemporáneas. El racismo epistémico y su fundamentalismo eurocéntrico derivado en la teoría social se manifiestan en discusiones sobre los derechos humanos y la democracia. Las epistemologías "no-occidentales" que definen los derechos y la dignidad humana en términos diferentes a Occidente, se consideran inferiores a las definiciones hegemónicas "occidentales" y, por ende, se excluyen de la conversación global sobre estas cuestiones. Si la filosofía y el pensamiento islámicos son representados como inferiores a Occidente por los pensadores eurocéntricos y la teoría social clásica en las ciencias sociales, entonces la consecuencia lógica es que no tienen nada que aportar a la cuestión de la democracia y los derechos humanos, y deben ser no sólo excluidos de la conversación global, sino reprimidos. La visión occidentalo-céntrica subyacente es que los musulmanes pueden elaborar parte de la discusión siempre y cuando dejen de pensar como musulmanes y asuman la definición liberal eurocéntrica hegemónica de democracia y derechos humanos. Cualquiera de ellos que intente pensar estas cuestiones desde su tradición (islámica) es inmediatamente sospechoso y acusado de fundamentalismo. Términos como democracia y derechos humanos islámicos se consideran un oxímoron dentro del "sentido común" hegemónico eurocéntrico.

La incompatibilidad entre el islam y la democracia se fundamenta en la inferiorización epistémica de las visiones provenientes del mundo musulmán. Hoy día, una artillería de "expertos" racistas/sexistas epistémicos en Occidente hablan con autoridad sobre el islam, sin un conocimiento serio de su tradición. Los estereotipos y mentiras repetidos una y otra vez en la prensa y las revistas occidentales terminan — como en la teoría de 
la propaganda nazi de Goebbels - tomadas como verdad. Como lo decía Edward Said, no hace mucho:

Un cuerpo de expertos sobre el mundo islámico ha crecido hasta hacerse prominente, y durante una crisis salen a la luz para pontificar con tono arrogante y dogmático ideas ya formuladas sobre el islam provenientes de programas noticiosos o de entrevistas. También parece haber habido un extraño renacimiento de ideas orientalistas canónicas, aunque previamente desacreditadas, sobre los musulmanes, por lo general consideradas personas no blancas -ideas que han logrado una alarmante preeminencia en un momento en que las tergiversaciones raciales o religiosas de todo otro grupo cultural ya no circulan con tal impunidad-. Las generalizaciones maliciosas sobre el islam se han convertido en la última forma aceptable de denigración de la cultura extranjera en Occidente; lo que se dice sobre la mente, el carácter, la religión o la cultura musulmanes como un todo no puede ahora decirse en la discusión imperante sobre africanos, judíos, otros orientales o asiáticos. Mi opinión es que la mayor parte de ello es una generalización inaceptable del tipo más irresponsable, y nunca podría usarse para cualquier otro grupo religioso, cultural o demográfico sobre la tierra. Lo que esperamos del estudio serio de las sociedades occidentales, con sus complejas teorías, sus enormemente diversos análisis de las estructuras sociales, las historias, las formaciones culturales y los lenguajes sofisticados de la investigación, deberíamos esperarlo también del estudio y la discusión sobre las sociedades islámicas en Occidente (Said, 1998: 11-16).

La circulación de estos estereotipos contribuye a la representación de los musulmanes como racialmente inferiores, criaturas violentas. De ahí, su fácil asociación con el "terrorismo" que justifica la impunidad del "terrorismo de Estado" y su proyecto de dominación imperial/colonial a escala mundial.

\section{EL CASO OCCIDENTAL DE TARIQ RAMADAN}

Es interesante analizar la reacción occidental ante un pensador islámico europeo crítico como Tariq Ramadan. Identificado a sí mismo como musulmán europeo, ha sido simultáneamente víctima de una campaña occidentalista y orientalista para distorsionar su imagen y pensamiento. En Francia no le es permitido hablar en las universidades, ${ }^{4} \mathrm{y}$ en Estados Unidos el Departamento de Homeland Security prohibió su entrada al

4 Durante los años en que Sarkozy fue ministro del Interior de Francia, a Tariq Ramadan se le prohibió hablar en las universidades públicas. 
país. ${ }^{5}$ La campaña de los medios de comunicación occidentales contra su pensamiento lo califica como una especie de extremista fundamentalista islámico, a pesar de que él es un reformador islámico progresista. Incluso, universidades occidentales, como la Universidad de Notre Dame (donde le ofrecieron el puesto de profesor en la cátedra Henry R. Luce, de Religión, Conflicto y Pacificación, antes de ser expulsado del país por el Departamento de Homeland Security) y la Universidad de Oxford en Inglaterra (donde actualmente es profesor visitante), reconocen sus contribuciones. La pregunta es: ¿Por qué un pensador musulmán europeo reformista (crítico del fundamentalismo islámico, de los actos suicidas, de la lapidación contra la mujer, del terrorismo, etc.), es atacado y tergiversado erróneamente como una especie de extremista fundamentalista islámico? Hani Ramadan, el hermano de Tariq, se ha declarado fundamentalista islámico y, a pesar de sus múltiples libros, nunca ha sido blanco de una campaña negativa occidental tan enorme como Tariq.

La respuesta consiste en que para Occidente es más difícil aceptar a un pensador reformista islámico progresista, crítico con el fundamentalismo euro-céntrico y con el fundamentalismo islámico, que a un pensador fundamentalista islámico declarado. Este último confirma todos los prejuicios islamófobos orientalistas construidos contra el islam, mientras que el primero desafía esas representaciones. Por eso, tanto The New York Times como Le Monde han dedicado las primeras páginas de sus diarios al "caso Tariq Ramadan". ${ }^{6}$ El primero debido a la política de seguridad interna (donde fue acusado falsamente de terrorista por haber donado

\footnotetext{
${ }^{5}$ Es importante señalar que en enero de 2010 la administración Obama eliminó la prohibición de Seguridad Nacional para que Tariq Ramadan pueda entrar a Estados Unidos.

6 Entre los muchos artículos publicados por Le Monde sobre Tariq Ramadan, véase el titular de primera página "Tariq Ramadan, sa famille, ses réseaux, son idéologie", del 23 de diciembre de 2003, y el artículo "Tariq Ramadan consultant de Tony Blair", del 25 de febrero de 2006. Cuando un diario llega a estar tan obsesionado como para dedicar el titular de la portada a investigar el sospechoso "doble discurso" de Tariq Ramadan, se sabe que está pasando algo desproporcionado y exagerado. The New York Times tiene una propaganda menos activa (tal vez porque Ramadan es menos conocido e influyente entre los jóvenes musulmanes de Estados Unidos) y versiones más equilibradas en comparación con Le Monde, pero aún con muchas insinuaciones y comentarios sospechosos. Entre los muchos artículos de The New York Times, véase el de primera página "Mystery of the Islamic Scholar who was Barred by the U.S., del 6 de octubre de 2004, y "World Briefing: Europe: Switzerland: Barred Islamic Scholar Gives up U.S. Teaching Post", del 15 de diciembre de 2004.
} 
dinero a organizaciones palestinas), y el segundo (mucho antes de su prohibición de entrada en Estados Unidos) acusándolo de fundamentalista. En Francia, así como en toda Europa Occidental, Tariq Ramadan es muy popular entre los jóvenes musulmanes europeos. Su mensaje a la juventud musulmana es que se puede ser europeo y musulmán al mismo tiempo. Esto desafía uno de los mitos más sagrados de la política de identidad europea (para ser europeo hay que ser cristiano o laico). Además, Ramadan pide a la juventud musulmana que ejerza sus derechos de ciudadanía, como europeos musulmanes, y que intervengan en la esfera pública reclamando igualdad y contribuciones a la sociedad. Esto ha sido demasiado subversivo para ser aceptado, tanto por los fundamentalistas islámicos como por las corrientes principales de europeos euro-centristas de derecha e izquierda. Así, la campaña islamófoba contra Tariq Ramadan va directamente al ataque de su pensamiento.

El diario francés Le Monde ha atacado activamente a Ramadán como un fundamentalista islámico que utiliza un "doble discurso" desde los tiempos en que fue expulsado de Francia en la década de los noventa. Más tarde, cuando se prohibió su presencia, se levantó en Francia la campaña de Le Monde contra el "doble lenguaje" de Ramadán, campaña que continúa hasta nuestros días. Lo interesante es el doble criterio y el racismo epistémico que hay detrás de esta acusación. Se aplican diferentes reglas de juicio cuando se trata de un pensador/a intelectual europeo de la tradición occidental, que cuando es un pensador/a intelectual europeo de la tradición islámica. Un intelectual atacado como promotor de un "doble discurso", es decir, "lo que dice y escribe no es realmente lo que cree", no tiene manera de defenderse a sí mismo.

La regla para juzgar el trabajo de cualquier intelectual se basa en lo que él/ella dice y escribe. Pero si la acusación es que lo manifestado por él/ella es falso, porque él/ella tiene un "doble discurso", entonces no hay autodefensa posible contra esa acusación. No importa lo que el intelectual acusado alegue en su defensa, se convierte tautológicamente en un argumento contra él/ella mismo/a. No importa cuántas veces Tariq Ramadan haya denunciado públicamente la opresión y la lapidación de las mujeres, el terrorismo, el fundamentalismo islámico, la visión fundamentalista del islam de su hermano, las visiones fundamentalistas del islam de Arabia Saudí y los talibanes, los actos suicidas, etcétera, Le Monde sigue atacándolo sin fundamentos, pues la única afirmación de este periódico es repetir una 
y otra vez que Ramadán tiene un "doble discurso". Las normas usadas para juzgar a Ramadan (el criterio del "doble discurso" sin una lectura seria de su trabajo ni un esfuerzo por mostrar evidencia) nunca se aplican a los intelectuales occidentales. El doble criterio de usar unas normas distintas para evaluar un intelectual "occidental" muestra que la islamofobia forma parte del racismo epistemológico del occidentalismo. En suma, la islamofobia no sólo se manifiesta en el mercado laboral, la educación, la esfera pública, la guerra global contra el terrorismo o la economía mundial, sino también en el campo de batalla epistemológico acerca de la definición de las prioridades y la formulación de instituciones en el mundo actual.

\section{BIBLIOGRAFÍA}

ERNST, C. W. (2003); Following Mohammad: Rethinking Islam in the Contemporary World. Chapel Hill y Londres: University of North Carolina Press.

CHALMERS, J. (2006); Nemesis: The Last Days of the American Republic. Nueva York: Metropolitan Books.

DUSSEL, E. (1994); 1492: El encubrimiento del Otro. Hacia el origen del "mito de la modernidad". La Paz: Plural Editores.

GRAHAM, M. (2006); How Islam Created the Modern World. Beltsville, Maryland: Amana Publications.

GROSFOGUEL, R. (2003); Colonial Subject. Berkeley: California University Press.

HUNTINGTON, S. (1997); The Clash of Civilizations and the Remaking of World Order. NuevaYork: Touchstone.

MALDONADO TORRES, N. (2006); "Reconciliation as a Contested Future: Decolonization as Project or Beyond the Paradigm of War", en Iain S. Maclean (ed.), Reconciliation: Nations and Churches in Latin America, Londres: Ashgate. , (2008); Against War. Durham: Duke University Press,

MERNISSI, F. (1987); Le Harem Politique. Le Prophete et le Femme. París: Albin Michel.

MOORE, C. (1977); Where Marx and Engels White Racists?: The Prolet-aryan Outlook of Marx and Engels, 2a. ed. Chicago, Illinois: Institute of Positive Education. En <http://pdfserve.informaworld. com/411649_915549761_745946075.pdf >. 
PERCEVAL, J. M. (1997); Todos son uno. Arquetipos, xenofobia y racismo. La imagen del morisco en la monarquía española durante los siglos XVI y XVII. Almería: Instituto de Estudios Almerienses.

RASHID, A. (2001); Taliban: Militant Islam, Oil and Fundamentalism in Central Asia. New Haven y Londres: Yale University Press.

RISEN, J. (2006); State of War: The Secret History of the CIA and the Bush Administration. Nueva York: Free Press.

SAID, E. (1979); Covering Islam: How the Media and the Experts Determine how we See the Rest of the World. Nueva York: Pantheon Books.

, (1981); Orientalism. Nueva York: Vintage Books.

(1998); Covering Islam: How the Media and the Experts Determine how we See the Rest of the World. Nueva York: Vintage Books.

SALAITA, S. (2006); Anti-Arab Racism in the United States: Where it Comes from and what it Means for Politics Today. Londres: Pluto Press.

SALIBA, G. (1997); Islamic Science and the Making of the European Renaissance. Boston: MIT Press.

TARIQ, A. (2002); The Clash of Fundamentalisms: Crusades, Jihads and Modernity. Londres: Verso.

\section{OTRAS FUENTES}

ENGELS, F. (1848); "French Rule in Algiers", en The Northern Star, 22 de enero, en MECW, vol. 6, pp. 469-472, citado en S. AVINERI (1968); Karl Marx on Colonialism and Modernization. Nueva York: Doubleday. (1853); "Turkey”, en New York Daily Tribune, citado en AVINERI, S., (1968); Karl Marx on Colonialism and Moderization, Nueva York: Doubleday.

(1858); New York Daily Tribune, 21 de julio, en MECW, vol.15.

GROSFOGUEL, R. (2006); "World-Systems Analysis in the Contex of Transmodernity, Border Thinking, and Global Coloniality”, en Review, vol. XIX, núm. 2.

(2007); "Los dilemas de los estudios étnicos estadounidenses: multiculturalismo identitario, colonización disciplinaria y epistemologías descoloniales", en Universitas Humanística, núm. 63, enero-junio, pp. 35-47. En: <http://www.javeriana.edu.co/Facultades/C_Sociales/universitas/63/ Grosfoguel.pdf $>$. 
GROSFOGUEL, R. (2008); "Para descolonizar os estudos de economia política e os estudos pós-coloniais: Transmodernidade, pensamento de fronteira e colonialidade global", en Revista Crítica de Ciências Sociais, núm. 80, marzo, pp. 115-147. Versión en inglés: <http://www.eurozine.com/ pdf/2008-07-04-grosfoguel-en.pdf>.

(2008); "Hacia un pluri-versalismo transmoderno decolonial", en Tabula Rasa, núm. 9, julio-diciembre, pp. 199-215. En: <http://www.revistatabularasa.org/numero_nueve/10grosfoguel.pdf $>$.

(2009); "Human Rights and Anti-Semitism after Gaza", en Human Architecture: Journal of the Sociology of Self-Knowledge, vol. VII, edición núm. 2, primavera, pp. 89-101. Véase versión castellana en: <http://www. javeriana.edu.co/revistas/Facultad/sociales/universitas/www/68/grosfoguel.pdf $>$.

, (2012); “El concepto de 'racismo' en Michel Foucault y Frantz Fanon: ¿Teorizar desde la zona del ser o desde la zona del no-ser?”, en Revista Tabula Rasa, núm. 16, enero-junio.

, (2013); "The Structure of Knowledge in Westernized Universities: Epistemic Racism/Sexism and the four Genocides/Epistemicides of the Long 16th Century", en Human Architecture, vol. XI, núm. 1.

MARX, K. (1853), “The Future Results of the British Results of the British Rule in India", citado en S. AVINERI, (1968); Karl Marx on Colonialism and Modernization. Nueva York: Doubleday.

, (1854); “The Outbreak of the Crimea-Moslems, Christians and Jews in the Otoman Empire", en New York Daily Tribune, 15 de abril, citado en S. AVINERI (1968); Karl Marx on Colonialism and Modernization. Nueva York: Doubleday.

PERCEVAL, J. M. (1992); “Animalitos del señor: Aproximación a una teoría de las animalizaciones propias y del otro, sea enemigo o siervo, en la España imperial (1550-1650)", en Áreas. Revista de Ciencias Sociales, núm. 4, Universidad de Murcia.

SUKIDI, M. (2006); “Max Weber's Remarks on Islam: The Protestant Ethic among Muslim Puritans", en Islam and Christian-Muslim Relations, vol. 17, núm 2, abril, pp. 195-205. 